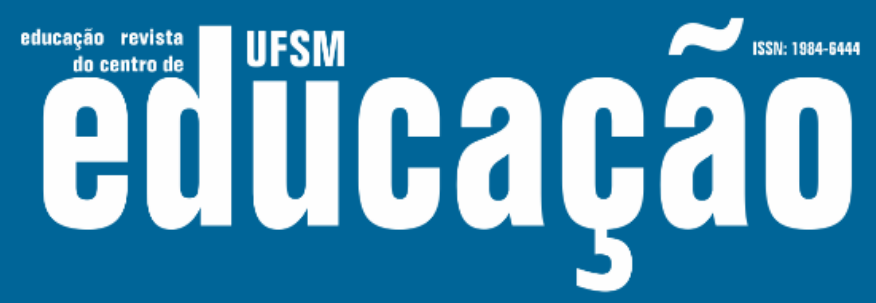

ISSN: 1984-6444 | http://dx.doi.org/10.5902/1984644435491

\title{
Proposta metodológica para o ensino das danças populares na Escola do Teatro Bolshoi No Brasil
}

Methodological proposal for the teaching of popular dances in the Escola do Teatro Bolshoi no Brasil

Marco Aurelio da Cruz Souza

Professor doutor na Universidade Regional de Blumenau, Blumenau, Santa Catarina, Brasil. marcoaurelio.souzamarco@gmail.com - https://orcid.org/0000-0002-9243-5372

Recebido em 05 de novembro de 2018

Aprovado em 07 de outubro de 2019

Publicado em 15 de maio de 2020

\section{RESUMO}

A formação do bailarino clássico e contemporâneo na Escola do Teatro Bolshoi no Brasil localizado em Joinville (SC) é baseado na disciplina rígida e metodologia da escola russa. Em minha tese de doutorado em Motricidade Humana na especialidade Dança, realizado na Faculdade de Motricidade Humana em Lisboa Portugal, busco entender qual o papel da disciplina danças populares na matriz curricular desta escola. Após as análises realizadas, apresento uma proposta metodológica para o ensino da dança popular que se chama "Dança popular, espaço coletivo de saberes". Acreditamos que enquanto componente curricular, a dança popular pode oportunizar aos professores 0 uso de novas estratégias pedagógicas favorecendo 0 reconhecimento da cultura brasileira, de novos processos criativos, e em dar "voz" aos alunos, aumentando a autonomia nas decisões tomadas. Isso resulta que o processo de formação de bailarino anda paralelo ao processo educacional, com foco na formação cidadã, e ainda oportunizando um processo de interdisciplinaridade. Esta reflexão realizada em torno das estruturas do vivido na Escola do Teatro Bolshoi no Brasil fez surgir a proposta baseada em princípios da arte e educação, gerando novas possibilidades de trabalhar o corpo sob a perspectiva de dança popular de matriz tradicional.

Palavras-chave: Dança Popular; Proposta metodológica; Ensino na educação nãoformal.

\section{ABSTRACT}

The classical and contemporary dancer's training at the Bolshoi Theater School in Brazil located in Joinville (SC) is based on the rigid discipline and methodology of the 


\section{H HW elithahá}

ISSN: 1984-6444 | http://dx.doi.org/10.5902/1984644435491

Russian School. In my doctoral thesis on Human Motricity, in the Dance specialty, held at the Faculty of Human Motors in Lisbon-Portugal, I try to understand the role of the popular dance discipline in the curriculum of this school. After the data analysis, I present a methodological proposal for the teaching of popular dance that is called "Dança popular, espaço coletivo de saberes". We believe that as a curricular component, popular dance can provide teachers the possibility of using new pedagogical strategies favoring the recognition of Brazilian culture, new creative processes, and giving "voice" to the students, increasing autonomy in the decisions made. This results in that the process of training of dancer goes parallel to the educational process, with focus on the citizen formation, and still opportunizing a process of interdisciplinarity. This reflection around the structures of the lived in the School of the Bolshoi Theater in Brazil gave rise to the proposal based on principles of art and education, generating new possibilities of working with the body from the perspective of traditional folk dance.

Keywords: Popular Dance; Methodological proposal; Teaching in non-formal education.

\section{Introdução}

"Formar é criar condições para que o outro se torne obra de si mesmo" Antonio Nóvoa

Durante os anos de 2013 e 2018 realizei o doutoramento em Motricidade Humana na especialidade Dança na Faculdade de Motricidade Humana em Lisboa Portugal, com a tese intitulada "A dança popular no processo de formação do bailarino clássico e contemporâneo: estudo sobre a Escola do Teatro Bolshoi do Brasil". O estudo teve a orientação da professora Doutora Ana Macara e foi submetido à apreciação do Comitê de Ética da Faculdade de Motricidade Humana, Lisboa Portugal e aprovado sob o parecer CEFMH 19/2015, por meio do C.A.A.E. 0024.0.268.000-10.

Estivemos de 2015 a 2017 na sede da escola para coletar os dados, e para isso realizamos entrevistas semi-estruturadas com os sujeitos da pesquisa: professor de dança popular ( $\mathrm{N}=1)$, professor de dança contemporânea $(\mathrm{N}=1)$, professor russo de dança clássica $(\mathrm{N}=1)$, professor brasileiro de dança clássica $(\mathrm{N}=1)$, estudantes de 


\section{F Hsy eltoaráto}

ISSN: 1984-6444 | http://dx.doi.org/10.5902/1984644435491

dança pertencentes ao núcleo de dança clássica $(\mathrm{N}=3)$, estudantes de dança pertencentes ao núcleo de dança contemporânea $(\mathrm{N}=3)$, bailarinos profissionais da Companhia Jovem da ETBB $^{1}(\mathrm{~N}=4)$ e gestores $(\mathrm{N}=2)$. Durante este período, foram observadas aulas de dança popular e contemporânea, que nos possibilitaram anotações em diário de campo e obtenção de registros fotográficos, possibilitando a aquisição de dados que contribuíssem para o enriquecimento das análises. O diário de campo não se caracterizou como um documento meramente descritivo. Era um documento no qual fazíamos anotações reflexivas, considerando nossas impressões sobre as ações dos professores e estudantes, as relações reveladas durante as aulas. Ao permanecer sentado num canto da sala, transformava em palavras minha experiência junto ao processo que estava acontecendo. Não havia ordem quanto à obtenção de imagens, anotações e reflexões. Havia, sim, pontos a serem observados e que nos interessava no momento para percebermos as metodologias utilizadas pelos professores, as relações interpessoais estabelecidas com os alunos, a existência hierárquica entre eles e a ocupação do espaço. O roteiro de observação estava dividido em 15 pontos.

Utilizamos estes dados para melhor interpretar as respostas obtidas nas entrevistas, problematizando-os e confrontando-os. Procuramos ainda, perceber o funcionamento da escola pesquisada enquanto lá estivemos, buscando complementar as informações a partir dos documentos oficiais ${ }^{2}$ da ETBB. A partir das discussões realizadas durante a escrita da tese, finalizamos a mesma apresentando uma proposta metodológica para o ensino das danças populares na Escola do Teatro Bolshoi no Brasil.

Para elaboração desta proposta, pontos importantes evidenciados no processo de formação de bailarinos da ETBB foram levados em consideração, como os relacionamentos pessoais durante as aulas (entre os próprios alunos e entre alunos e professores), os processos de pesquisa, criação e os ensaios de trabalhos coreográficos de danças populares, e conhecimentos específicos dos professores sobre cultura e dança popular. Acreditamos que construir esta proposta a partir das evidências deste estudo é dar credibilidade as inúmeras vozes participantes. 


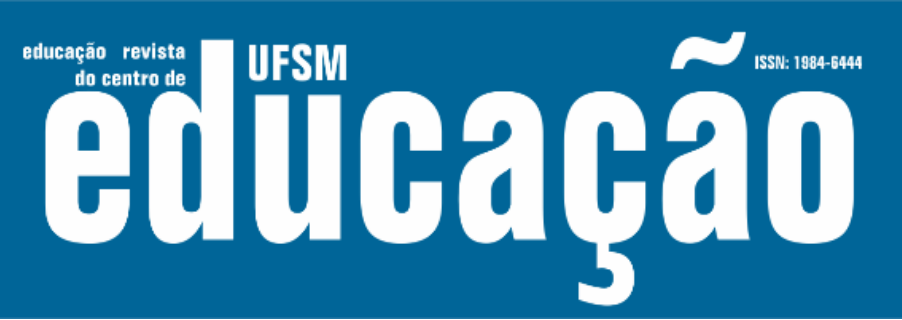

ISSN: 1984-6444 | http://dx.doi.org/10.5902/1984644435491

Desta forma, esta proposta metodológica alicerça-se em três pilares que consideramos fundamentais para seu êxito: (1) formação continuada para os professores de dança popular da ETBB; (2) aulas com centralidade na aprendizagem dos alunos a partir do compartilhamento de saberes; (3) relacionamento pessoal.

Diante da infinidade de possibilidades conceituais que as danças populares atingem e que estivemos a procura durante o desenvolvimento do estudo, tentando encontrar uma terminologia própria, trataremos nessa proposta como "dança popular de matriz tradicional". Partimos então da premissa de que ensinar dança popular de matriz tradicional para crianças e adolescentes é cumprir objetivos de um programa de educação em dança de forma consciente, os quais serão alcançados na medida do cumprimento de caminhos adequados ao desenvolvimento de capacidades físicas e morais dos estudantes (BREDEKAMP e COPPLE, 1997). Contudo, a premissa para a implementação de um trabalho educativo sério e eficiente é, antes de tudo, o reconhecimento de sua importância.

No que tange ao primeiro pilar intitulado "formação continuada para os professores de dança popular da ETBB", ressaltamos que esta exige saberes específicos sobre esta área para a busca de novos conhecimentos, novas habilidades e atitudes pedagógicas que possibilitem um processo de educar mais democrático. Sugerimos que estas estejam em consonância os princípios educacionais de Freire (1978, 1996, 2007), que defende a necessidade da busca autonomia e emancipação dos estudantes. Para tanto, as formações continuadas precisam estar previstas no calendário acadêmico da ETBB. As possibilidades que vislumbramos para não modificar a organização e o funcionamento da Escola são: formações específicas de dança popular de matriz tradicional na semana pedagógica de janeiro e julho; formações durante o período em que um profissional das danças populares vem para ETBB para montar os trabalhos coreográficos; ou ainda formações aos sábados durante 0 ano letivo.

Durante a formação continuada e a sua prática docente, o professor de dança popular precisará refletir sobre a realidade dos alunos com quem trabalha, e entender que esta encontra-se em constante transformação. Desta forma, ao reavaliar suas aulas, num processo permanente de planejamento e numa postura de atitude positiva, 


\section{工 Usm 2 Althapã}

ISSN: 1984-6444 | http://dx.doi.org/10.5902/1984644435491

o professor estará auxiliando na construção e fortalecimento da identidade profissional do professor de dança popular de matriz tradicional e no aprendizado do aluno. Sendo assim o professor precisa estar atento que:

aprender é um exercício constante onde o professor precisa estar atento e preparado para essa construção do saber. Investir em energias cognitivas e imaginárias de maneira que possa sintetizar as ideias mais significativas em um exercício de apropriação do conhecimento. (SIMÃO, 2012, p. 631).

Ressaltamos isso, pois para dar conta das demandas educacionais da contemporaneidade, os professores precisam estar em busca de atualização para ampliar sua gama de estratégias de ensino na tentativa de motivar e engajar seus alunos. Algumas estratégias possíveis para as aulas desta proposta metodológica serão apresentadas mais a frente, e que não servem como modelo fechado, e sim como ponto de partida, podendo ser revisitadas, modificadas, reconstruídas.

No segundo pilar, aulas com centralidade na aprendizagem dos alunos a partir do compartilhamento de saberes, recorremos a Libâneo (1994), por sugerir que o aluno deve ser direcionado à solução de problemas, explorando sua autonomia e criatividade. O professor assume assim uma postura de mediador, ou seja, uma pessoa que durante o processo educacional lançará os estímulos e dará suporte constante para que os alunos evoluam dentro da proposta idealizada. Sendo assim, desconsidera-se a estrutura hierárquica tradicional na qual apenas o professor detém o saber e o aluno recebe o conhecimento.

A ideia da estratégia de ensino é: criar ambiente favorável à aprendizagem; apresentação de uma situação-problema a respeito da manifestação popular a ser trabalhada em sala para que o aluno mobilize seus conhecimentos prévios e vá à busca de novos para resolvê-la. Durante a aula, o professor incentivaria os alunos a encontrarem sua própria voz nos momentos de criação e interpretação das obras. Durante a interpretação (performance, ensaios) surge o momento de apreciação artística do conhecimento que está sendo produzido. Estes três processos (criação, performance e apreciação) se aproximam das proposições de Ana Mae Barbosa (1991) para o ensino das artes; Smith-Autard (2002) para o ensino da dança enquanto 


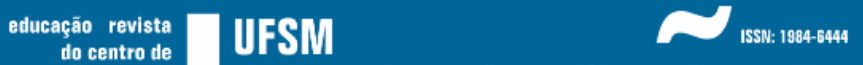 FutlaghaO}

ISSN: 1984-6444 | http://dx.doi.org/10.5902/1984644435491

arte e McCutchen (2006) para o ensino da dança enquanto arte educação. Estas estratégias de ensino dialogam com o proposto por Perrenoud (1995, p. 28): "organizar as interações e atividades de modo que cada aluno se defronte constantemente com situações didáticas que Ihe sejam as mais fecundas". Esta é também uma das proposições de Paulo Freire (1996), que sugere que tanto professores como alunos, deveriam assumir-se como sujeitos da produção do saber. Os saberes que cada aluno trás para sala de aula surgem, nessa proposta metodológica, como dispositivos de poder e legitimam-se pelo conhecimento produzido. Gehres (2008) afirma que o ensino deve visar formar um indivíduo capaz de manipular e sintetizar as informações, e aprender a usar o poder e as possibilidades de movimentar-se em diálogo com diferentes formas de dança. Estes movimentos serão potência para os processos criativos nas aulas de dança popular de matriz tradicional desta proposta.

Vislumbramos que toda esta proposição está de acordo com a Proposta Pedagógica da ETBB (2014), e ao colocá-la em prática, a Escola estaria apta a garantir que os alunos iniciassem, permanecessem e participassem ativamente de todo o processo de formação cidadã por meio da dança. A construção de conhecimentos, de habilidades específicas para a dança e atitudes pertinentes aos objetivos planejados, estariam em conformidade com o documento citado:

[...] desenvolver no aluno senso crítico e conhecimento da ética e estética que vão além do conhecimento técnico devido à preocupação também com a personalidade, criando neles a autonomia para futuras escolhas, que oportunizem profissionais de alto nível na área artística (dança). (BOLSHOI, 2014, p. 8).

É importante que as aulas enfatizem o prazer de dançar e o envolvimento total dos alunos, superando a proposta de concentração na execução mecânica e repetitiva dos movimentos envolvidos nas coreografias.

Marques (2007) defende que a formação em dança na contemporaneidade deveria pressupor o desenvolvimento de um pensamento crítico e a sensibilidade estética e artística dos alunos, o que se distancia da ideia de conhecimento transmissivo. A escola, nessa perspectiva, passa a ser vista enquanto espaço cultural 


\section{N Usm Elthapal}

ISSN: 1984-6444 | http://dx.doi.org/10.5902/1984644435491

que oportuniza uma parcela de tempo para a formação humanística e cultural. Nesse sentido, os alunos assumiriam papel central no processo de ensino e aprendizagem, conforme sugere Torre (1998, p. 83): "Deixar o rol de consumidores para passar a sermos gerenciadores de conhecimento e atuar como agentes de mudança, em lugar de estarmos sujeitos a este". Na proposta pedagógica da ETBB (2014), encontramos que a educação nessa Escola deve ser baseada no aprender a conhecer, a fazer, a viver junto, a ser, o que vai de encontro a esta nossa proposição.

O terceiro pilar desta proposta tem o foco nos relacionamentos pessoais que acontecem em sala de aula. Entendemos que o ato de ensinar embasa-se a partir da interação entre as relações de compromisso com o outro e com si mesmo, num diálogo constante e democrático, surgindo novas formas de relacionamento entre professor e alunos.

[...] o diálogo é uma exigência existencial. E sendo um encontro solidário a reflexão e a ação de seus sujeitos encausados junto ao mundo que deve ser transformado e humanizado, não pode reduzir-se a um mero ato de depositar idéias de um sujeito em outro. Nem converter-se tão pouco em uma simples mudança de idéias consumadas por seus permutantes. (FREIRE, 2007, p. 105, tradução nossa).

Estas novas relações que passariam a surgir nesse espaço coletivo de saberes (sala de aula) tornar-se-iam horizontais e poderiam provocar transformações no processo educacional em dança nessa Escola, garantindo a cada estudante da ETBB seu espaço e voz nas decisões do grupo. O que sugerimos efetivamente nesse pilar é a possibilidade de existir uma relação de um com o outro sem protagonismo somente do professor ou de um ou outro estudante, ou seja, uma relação dialógica em busca de maior liberdade e democracia no processo educacional, conforme já sugeria há muito tempo Paulo Freire (1978). A aprendizagem surgirá também a partir das interações entre os participantes das aulas. Pozo (2003) chama este processo de aprendizagem social e tenta o definir como sendo "[...] a aquisição de pautas de comportamento e de conhecimentos relativos às relações sociais" (POZO, 2003, p. 73). Isso significa que por meio destas práticas de interação social espera-se do aluno 


\section{F Eutiratá}

ISSN: 1984-6444 | http://dx.doi.org/10.5902/1984644435491

a "aquisição e mudança de atitudes, valores, normas, etc. que são adquiridos como consequência de pertencermos a certos grupos sociais" (POZO, 2003, p. 73).

Defendemos desta forma, que as aulas de danças devem ultrapassar 0 propósito de aquisição de um saber corporal específico, de conhecer uma determinada modalidade de dança para realizar apresentações artísticas, de responder a objetivos procedimentais de aprendizagem e execução técnica. Neste sentido, o ato educativo e a experiência de cada aluno formam um espaço coletivo de construção de saberes, em que o universo popular é reconhecido e valorizado como campo de conhecimento equivalente a qualquer outro campo de saber em dança. $A$ ideia é superar a perspectiva do "só fazer", tendo como reflexo a construção de novos saberes, como por exemplo, "o saber sobre", que estão relacionados aos conceitos e "o saber ser" que estão relacionadas as atitudes dos estudantes. Os objetivos destas aulas passariam, portanto, a focar também nos conhecimentos conceituais, atitudinais e relacionais de aprendizagem (Coll et al, 2000; Zabala, 1998; Libâneo, 1994), bem como a execução, a criação e a apreciação.

Os processos artísticos em dança devem andar lado a lado com os processos educacionais, pois entendemos que estes podem surgir a partir das relações estabelecidas entre os participantes do grupo, incentivando valores como alteridade, generosidade e compartilhamento.

As aulas nessa perspectiva englobam inúmeros aspectos simultâneos, como a subjetividade dos indivíduos, a consciência de um fazer dança relacionado aos seus significados e contextos sociais (Marques, 2010). Inevitavelmente, o descobrir sentidos em outras pessoas e corpos, a partir de diferentes tessituras sociais, ocorrerá por meio de um processo dirigido de autoconhecimento. Tal processo permitirá que os fenômenos sociais sejam vistos e compreendidos por diferentes perspectivas e ângulos, conforme sugerem os autores Fuhrmann (2008), Godoy (2013) e Sawaia (2014).

Acreditamos que as danças populares enfatizam a criatividade expressiva do corpo $^{3}$ dançante, bem como o pensar sobre a técnica corporal em diálogo com outras técnicas de dança acadêmicas, auxiliando no processo de formação humana e artística de forma integrada. Freire (1978) já assinalava que os processos de 


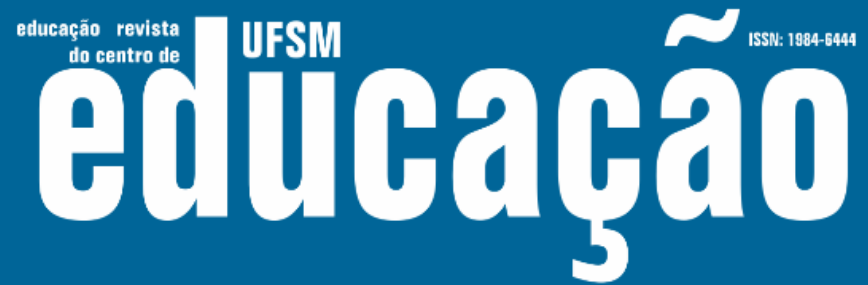

ISSN: 1984-6444 | http://dx.doi.org/10.5902/1984644435491

apropriar-se do conhecimento já existente e criar novos conhecimentos são simultâneos e intersignificam-se. Nesse escopo, quando propício, o professor pode e deve corrigir gestos, viabilizar espaços para treinos, aprimorar elementos técnicos, para que o aluno evolua dentro de suas possibilidades de aprendizagem. Ressaltamos que isso não deve ser tomado como fator mais importante, suprimindo as experiências com as manifestações, bem como, o espaço de criação.

Trabalhar as danças populares com crianças e adolescentes requer dos profissionais muita sensibilidade e, igualmente, a formulação e utilização de uma metodologia capaz de estimular e reconhecer as potencialidades e as experiências brincantes de cada aluno. No ambiente da ETBB, as aulas servirão como forma de resistência contra o pensamento hegemônico da dança acadêmica, que compreende o professor como único detentor e transmissor do conhecimento. O propósito é de fortalecer o sentimento de pertencimento a um lugar que funcione como elemento de (re)construção de conhecimentos, potente para proporcionar mudanças significativas nas vidas dos envolvidos, professores e alunos. Esta proposta tem a experiência artística/estética e as relações pessoais como o foco do trabalho pedagógico e reconhece o corpo na sua integralidade, caminhando na contramão de estruturas tradicionais do ensino da dança. Na proposta de Arte do Movimento, Laban (1988) argumenta que ação corporal é conceituada como uma correlação entre os fatores emocionais, físicos e intelectuais do bailarino (RENGEL, LUCENA, 2015). Sendo assim, a ideia de ação não se restringe a algo somente funcional, ela se amplia para o todo que é e que constitui cada pessoa. O termo ação corporal nesse caso é entendido a partir do conceito corponectiva de Rengel (2007), no qual, os processos sensório-motores são inseparáveis dos processos de cognição.

\section{Pressupostos que nos guiam}

Após estas considerações iniciais que nos fizeram alinhar os pensamentos, passamos para o desenvolvimento da proposta explicitando nossas decisões. Inicialmente destacamos que para a formulação desta proposta metodológica no que tange o trabalho realizado em sala de aula, utilizamos pressupostos teóricos de 


\section{Aitloab̧ão}

ISSN: 1984-6444 | http://dx.doi.org/10.5902/1984644435491

autores como Batalha (2004), Marques (2010), Santos (1997), Van Gennep (2004), Laban (1988). Ao propor a metodologia intitulada Dança no Contexto, Marques (2010) sugere que o aluno não seja visto como um objeto para o depósito de conhecimento de fora, mas como um ser humano, pensante e criador, capaz de participar ativamente de um processo de trocas e construção de saberes em sala de aula. Já Santos (1997), estabelece quatro objetivos fundamentais e complementares no ensino da dança: $\operatorname{cognitivos}^{4}$, sociais ${ }^{5}$, afetivos ${ }^{6}$ e físicos ${ }^{7}$. Batalha (2004) considera que um bom professor de dança é aquele que satisfaz requisitos fundamentais: é um artista, tem qualidades pedagógicas e qualidades humanas. Acrescentamos que, de modo específico, para ser um bom professor de dança popular é necessário possuir vivências neste campo de atuação, ter frequentado cursos na área e realizar pesquisas sobre cultura popular. Ainda para Batalha (2004), o professor deve ser o animador de experiências criativas, estar apto a dinamizar estados afetivos positivos do/no grupo, emitir estímulos e atuar como facilitador de críticas fundamentadas durante o processo formativo. Para referenciar as qualidades necessárias a um professor de dança popular, precisamos pensá-la ao nível de intencionalidade, previsibilidade e eficácia, visto que todo problema pedagógico consiste em encontrar os procedimentos adequados para acompanhar o aluno durante o seu processo de formação. Laban (1988) propõe que o movimento se tornasse um caminho para a liberação das possibilidades expressivas e comunicativas de cada pessoa a partir de suas experiências.

Nas aulas de dança popular de matriz tradicional, devem-se ensinar para além das capacidades físicas e artísticas, a relação com a ancestralidade, conhecimentos sobre si mesmo, reconhecendo o corpo como campo integrado de conhecimento cultural e social. Trata-se de uma área de estudo e atividade multicultural, que expõe os alunos ao contato com danças variadas e originadas em diversas partes do mundo, as quais representam vários tempos históricos e sociais e, ao mesmo tempo, mostram como diferentes culturas, nações e pessoas se conectam e inter-relacionam (WARDLE, 1999). Talvez a principal vantagem de ensinar dança popular de matriz tradicional para crianças e adolescentes é proporcionar, de maneira divertida e 


\section{F Hsy Eutiratá}

ISSN: 1984-6444 | http://dx.doi.org/10.5902/1984644435491

amorosa, conhecimento cultural por meio de uma atividade artística e física promotora do respeito ao diferente.

Acreditamos que exista uma grande relação entre os rituais e as danças populares em função do fator da presença, da ancestralidade. Van Gennep (18731957) é um antropólogo alemão que em "Ritos de Passagem" ${ }^{8}$ " debruçou-se nos estudos sobre os processos de transformação que ocorrem nas comunidades a partir de um conjunto de dados etnográficos. Estudou sobre os rituais e como eles estavam relacionados com a transição das mudanças sociais nas vidas dos indivíduos refletindo na vida comunitária, que ele denominava de ritos de passagem. Problematizou as relações dos indivíduos, grupos e posições em determinado contexto social. Contribuiu muito para os estudos do folclore europeu propondo a substituição da orientação histórica e de busca das origens, por uma abordagem etnográfica comparativa.

Van Gennep (2004) decompõe os ritos de passagem em três categorias ou fases: ritos de separação, ritos de transformação e ritos de integração, para melhor entender o funcionamento das passagens e a transformação nas comunidades.

Na primeira fase, os indivíduos são separados do seu lugar comum, do seu cotidiano, para adentrar num novo espaço diferenciado do comum. Há, desta forma, uma ruptura com sua história presente, permitindo aos indivíduos, uma possibilidade de evolução no grupo social, em termos de igualdade de oportunidades. No caso da ETBB os alunos estão acostumados a um determinado tipo de comportamento dentro e fora das aulas de dança, pelo qual são classificados e avaliados diariamente. Nesse sentido, ao entrarem na aula de dança popular de acordo com a nossa proposta, as ordens sociais são suspensas. Os participantes por estarem fora de suas zonas habituais de controle poderão ter voz. Quebra-se uma fronteira importante, concedendo espaço a nossa cultura nativa.

Na segunda fase, os participantes passam por experiências em busca de uma nova identidade. No caso de nossa proposta estará relacionado ao terceiro ponto, onde o fazer dança popular, depende deles assumirem-se dança popular, deles vivenciarem, pesquisarem, encontrarem sentidos nas manifestações populares brasileiras. 


\section{N

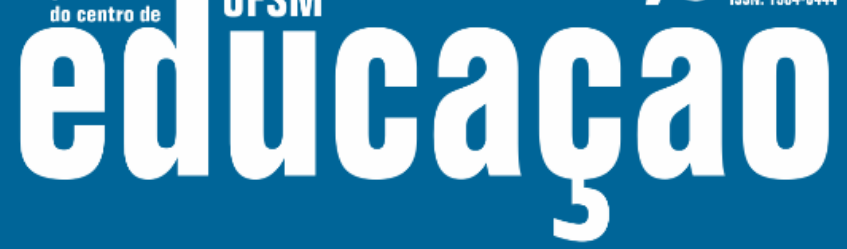

ISSN: 1984-6444 | http://dx.doi.org/10.5902/1984644435491

$\mathrm{Na}$ terceira fase do rito de passagem, trata-se um momento de integração, de preparar os indivíduos para voltar à comunidade, ao seu cotidiano, porém espera-se que num estado diferente. O participante transformado volta com uma nova identidade. No caso de nossa proposta metodológica, no momento do rito final, faz-se uma tomada de consciência dos pontos trabalhados em sala e tenta-se instigar nos alunos a importância de cada um deles no processo, pois a presença e participação de cada um deles é que faz a diferença no grupo. Instiga-se um espírito cidadão, comunitário.

\section{Dança popular: espaço coletivo de saberes}

Nomeamos nossa proposta metodológica de ensino na ETBB como Dança popular: espaço coletivo de saberes, posto que acreditamos na abrangência e complexidade dos conhecimentos envolvidos na matéria em questão, bem como, na potência de construção de conhecimentos de modo grupal integrado. A necessidade dos estudantes de dança saber lidar criativamente e criticamente com a diversidade de informações a que são expostos em sala de aula, nos ensaios e espetáculos lhes exige uma atitude ético-estética. Esta pode ser pensada como a capacidade de acolhimento de toda diversidade de saberes do grupo, que se transforma em ação.

Inicialmente, a sugestão é a de que os alunos frequentem duas aulas semanais, com a carga horária de 45 minutos cada. Somente assim o trabalho terá resultados efetivos. As aulas estruturam-se em quatro momentos distintos: 1 - Acolhimento; 2 Jogo; 3 - Conexão com a comunidade cultural9; 4 - Rito final.

O acolhimento diz respeito a um ritual inicial, realizado para que cada aluno perceba e sinta a presença do outro, com o qual compartilhará o espaço e o tempo da aula de dança popular, bem como, trocará experiências e impressões sobre a aula que virá.

O jogo tem duas possibilidades de utilização. Na primeira, é utilizado como warm up para preparar o corpo para as demais partes da aula. $O$ warm up diz respeito não somente a uma preparação muscular, mas a práticas que trabalhem a atenção e os diferentes modos de percepção ativa dos participantes. Na segunda possibilidade, 


\section{T Hsm entubagá}

ISSN: 1984-6444 | http://dx.doi.org/10.5902/1984644435491

o jogo é investido enquanto brincadeira, em atividades que primam pela diversão e engajamento dos estudantes. Trabalham-se modos de relação e a espontaneidade expressa por meio de movimentos. A brincadeira é útil para colocar todos num patamar de igualdade, derrubar hierarquias e julgamentos pré-concebidos. Os jogos aqui apresentados possuem uma estreita ligação com o ato performático e com a improvisação em grupo.

$\mathrm{Na}$ terceira parte da aula, alunos e professores conectam-se com a comunidade cultural, com o propósito de construir e aprofundar conhecimentos sobre diferentes danças populares e seus contextos.

Para fechar, o rito final promove o encerramento do ciclo da aula.

Diante do exposto apresentamos os objetivos e a forma de avaliação desta proposta metodológica para o ensino da dança popular de matriz tradicional:

\section{Objetivo Geral desta proposta metodológica}

- contribuir para a formação continuada do professor de dança popular para este que possa focar no desenvolvimento de habilidades essenciais do ser bailarino/cidadão na contemporaneidade (autonomia, alteridade, cooperação, cuidado com o próximo, comprometimento com o grupo, responsabilidade, espírito de equipe, ético e estético, senso de organização), a partir de metodologia centrada no aluno.

\section{Objetivos específicos desta proposta metodológica}

- compreender o espaço da aprendizagem em dança popular de matriz tradicional como espaço de vivência e criação coletiva;

- compreender que professores e alunos são sujeitos corresponsáveis pelo processo de aprendizagem e compartilhamento de saberes em dança;

- ser ativo no processo e perceber a aula de dança popular como local de experiências artísticas, estéticas e investigativas;

- desenvolver-se nas interações pessoais;

- aprimorar as habilidades artísticas, motoras, emocionais, cognitivas e culturais e perceber que estão interconectadas; 


\section{Us: Eutroará}

ISSN: 1984-6444 | http://dx.doi.org/10.5902/1984644435491

- oferecer aos professores de dança popular a garantia de espaço de formação continuada.

A avaliação deverá ser processual e descentralizada, podendo ser efetivada por todos os envolvidos, não apenas pelos docentes. Nessa perspectiva, considerada de modo interpretativo, o professor ao invés de querer resultados precisos em termos de movimentação sistematizada em frases de movimento ou coreografias, manteria o diálogo em processo com a turma na tentativa de contribuir para o aprendizado de cada estudante. Para Doll Jr. (1997), a avaliação é tida como um processo de negociação entre os sujeitos e assuntos tratados em determinado período de tempo, com o propósito de transformação. Desse modo, a avaliação é tida aqui como parte do processo de aprendizagem e não como instância de verificação e punição. Isso contraria as práticas de avaliação existentes na ETBB e que está diretamente associada a "uma epistemologia e realidade estáveis e uma pedagogia transmissiva" (DOLL JR, 1997, p. 188).

$\mathrm{Na}$ sequência, apresentamos cada uma das fases de nossa proposta metodológica, detalhando objetivos de cada parte das aulas, conteúdos e estratégias concernentes.

\section{Acolhimento (Duração estimada: 5 a 7 minutos).}

Os alunos da ETBB são oriundos de diferentes classes sociais e contextos culturais, e quando entram em uma sala de aula para fazer dança clássica, precisam portar-se conforme as regras estabelecidas: silêncio, atenção e trabalho. O individualismo faz parte do processo. Acredita-se que não se pode perder tempo para aquisição das habilidades necessárias para se dançar este estilo de dança. Não há tempo para socializar nesse tipo de aula, e desta forma, nessa proposta metodológica para as aulas de dança popular pode-se oportunizar isso as crianças e adolescentes. A primeira parte da aula é chamada de acolhimento, e é pensada como sendo um rito inicial em que todos podem se ver, se tocar, falar uns com os outros e vivenciar sua forma de ser no mundo. É um momento de partilhar este tempo e este espaço, e perceber a sua presença em relação com a presença do outro. Espera-se criar uma 


\section{T Hsm

ISSN: 1984-6444 | http://dx.doi.org/10.5902/1984644435491

atmosfera onde as trocas corpóreas permitam a criação de novos sentidos para o bailarino. Segundo Rodolpho (2004), os ritos concedem legitimidade para organizar a posição, o valor e as visões de mundo do sujeito, facilitando a compreensão de suas crenças e valores oriundos de seu meio social. Gennep (2004) afirma que os ritos podem assumir determinadas classificações, e podem ser simpáticos ${ }^{10}$ e de contágio $^{11}$, diretos ${ }^{12}$ e indiretos, bem como positivos ${ }^{13}$ e negativos. Este primeiro contato uns com os outros contribui para uma reorganização mental do aluno em relação ao que será realizado, desligando-se do contexto onde estavam.

\section{Objetivos de ensino:}

- Criar um ambiente favorável para a prática da dança popular;

- Favorecer o autoconhecimento;

- Propiciar a conexão de cada indivíduo com o grupo;

- Despertar o sentimento de pertencer;

- Incentivar o aluno a assumir responsabilidades para com o grupo;

\section{Objetivos de aprendizagem:}

- Expressar-se e posicionar-se como membro do grupo;

\section{Conteúdos:}

- Sentimento de pertencimento.

- Valores coletivos (responsabilidade, respeito, paciência, etc.).

\section{Estratégias:}

Práticas que promovam diferentes modos de encontro: do corpo consigo mesmo e entre corpos. Nesse ritual de acolhimento, sugere-se que os alunos caminhem no espaço em que a aula acontece ao seu ritmo e em qualquer direção, compartilhando a energia dos demais. Ao encontrar um colega, abrace-o fortemente, converse brevemente, faça-o sentir-se importante nessa aula. Para Shapiro (1998), a dança nesse contexto deixa de ser um objeto a ser ensinado e passa a ser uma vivência na qual os participantes interagem com a dança para a construção de uma 


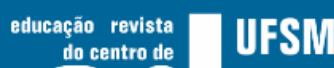 Eutiratá}

ISSN: 1984-6444 | http://dx.doi.org/10.5902/1984644435491

existência. O professor deve garantir que todos se abracem. Torna-se indispensável que os participantes concentrem-se nesse rito inicial de acolhimento, para que se abram corporalmente e se conectem consigo mesmo, com o outro, com o grupo. Tal atitude contribuirá para moldar um corpo disponível para as demais partes da aula.

Jogo (Duração estimada: 10 minutos).

Nessa parte da aula, os alunos afetam-se com o outro e constroem uma identidade coletiva por meio do ato de jogar, brincar e improvisar. A autonomia é estabelecida para colocar-se em movimento, bem como, para o estabelecimento de relações com os mais diversos elementos da aula - o próprio corpo e o outro (tudo o que difere de si mesmo, seja pessoa ou objeto. Exemplos: professor, espelho, chão, espaço, etc.) (KISHIMOTO, 1999; FRIEDMANN, 1996; CARDOSO, 2004). Essa atmosfera valoriza o fazer popular como ato mobilizador da ação e da intenção coletiva, nas relações de alternância e de entrelaçamento entre o que é individual e o coletivo.

O brincar, o estar em roda, o tocar no colega e olhar em seus olhos, são ferramentas fundamentais para este momento da aula. Desta forma, cria-se um "espaço coletivo de saberes". Neto (2003, p. 5) considera o jogo "uma das formas mais comuns de comportamento durante a infância e altamente atractiva e intrigante para os investigadores interessados nos domínios do desenvolvimento humano, educação, saúde e intervenção social". A ideia do jogar visa promover o entusiasmo do grupo, de tal maneira que se motive a explorar novas possibilidades de movimentos a partir das matrizes populares. Cada jogo possui uma infinidade de variações que podem ser desenvolvidas ao longo do processo e podem promover outros modos de interação com os corpos e seus movimentos e a partir desses elementos conceituais e das propriedades do movimento. A hora do jogo é um momento de liberação e transformação da realidade de uma aula de dança clássica, na qual os alunos precisam estar em silencio e obedientes. Nesse tipo de atividades Shapiro (1996) sugere que os alunos passam a ser os sujeitos de sua própria história e suas escolhas. 


\section{T Hsm

ISSN: 1984-6444 | http://dx.doi.org/10.5902/1984644435491

\section{Objetivos de ensino:}

- Estruturar um corpo adaptável em diferentes situações;

- Estimular o desenvolvimento de aspectos cognitivos (antecipação, hipóteses, ordenação, classificação);

- Ampliar a socialização dos alunos;

- Desenvolver capacidades físicas e psicomotoras;

- Despertar a imaginação criativa dos alunos;

\section{Objetivos de aprendizagem:}

- Ser corpo sujeito;

- Treinar a habilidade de improvisação;

- Reconhecer o jogo como componente dos fatos simbólicos e sociais da cultura popular brasileira;

\section{Conteúdos:}

- Jogos simbólicos, populares, de improviso, dramáticos, de composição.

\section{Estratégias:}

As operações práticas dos jogos devem voltar-se aos interesses dos alunos, levando em consideração experiências já adquiridas em sala de aula e suas histórias de vida. As tomadas de decisões justificam-se em razão dos objetivos, conteúdos e estratégias escolhidas e relacionadas aos desejos do grupo. Pode-se pedir que os alunos indiquem jogos das regiões de onde vieram e ou de sua preferência. Passa-se por escolhas individuais e coletivas, oportunizando momentos de convivência e aprendizagem cidadã, na qual as opiniões precisam ser respeitadas, seja da maioria, seja da minoria. Com o decorrer das brincadeiras o professor pode ir contextualizadoas, e até mesmo tornando-as mais complexas, favorecendo a imaginação criativa dos alunos e o ser corpo. 


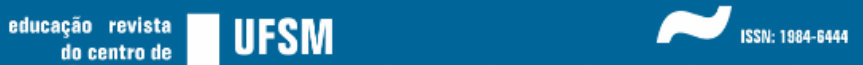 Eutlathat
}

ISSN: 1984-6444 | http://dx.doi.org/10.5902/1984644435491

Conexão com a comunidade cultural (Duração estimada: 20 a 25 minutos).

Nesta parte da aula, o professor deve pesar o conhecimento e as experiências anteriores dos alunos conforme propõe Marques (2010), para que o ensino da dança popular seja relevante e apropriado aos mesmos. Assim, aumentará o interesse e o envolvimento do estudante nas atividades. Neste momento, pode ocorrer uma combinação de ações, como a demonstração da dança pelo professor com a exploração rítmica, motora e simbólica dos movimentos. Sugere-se trabalhar a partir de quatro proposições estabelecidas por Laban (1971): conhecimento do corpo ${ }^{14}$, consciência espacial ${ }^{15}$, senso de esforço ${ }^{16}$ e relacionamentos ${ }^{17}$, sempre buscando promover a espontaneidade e criatividade dos alunos. As habilidades expressivas da dança popular, seus conceitos e sua simbologia, devem ser explorados de forma lúdica, para acessar a cognição de acordo com os mecanismos de processamento de informações. O aumento da conscientização e sensação de movimento na dança pode significar tanto o desempenho adequado da técnica, quanto a compreensão conceitual de como e por que esta técnica é moldada. A materialidade dos corpos ativos dos alunos no processo ganha peso e autonomia, e consequentemente transforma e renova as concepções de dança popular. Deixa-se de lado o esforço de uma representação de personagens comum no contexto das danças clássicas, e busca-se uma fisicalidade real pertencente a cada um deles. É outro nível de relação com os seus corpos. Sobre estes momentos, Diniz (1997, p. 17-18) afirma que:

\begin{abstract}
A idéia é incentivar o aluno a pesquisar, a contextualizar e compreender o fato pesquisado, cruzar as informações obtidas com a realidade numa perspectiva interdisciplinar e lúdica, selecionar temas para a composição coreográfica e refletir sobre a articulação do tema e de sua estrutura temática. Finalmente, após a elaboração coletiva do projeto do trabalho a ser realizado, é o momento de dar forma física através da montagem das coreografias.
\end{abstract}

Esta parte da aula oportuniza que os alunos coloquem em prática 0 vocabulário de movimentos descobertos e mapeados nas pesquisas iniciais e no ato de improvisar. Surge uma multiplicidade de formas expressivas justapostas ao longo desta parte da aula (voz, dança, dramaturgia). Nesse momento, é trabalhado o que 


\section{T Hsm

ISSN: 1984-6444 | http://dx.doi.org/10.5902/1984644435491

Van Gennep (2004) chamou de ritual de calendário ${ }^{18}$, como o carnaval e os folguedos de boi.

\section{Objetivos de ensino:}

- Implementar o multiculturalismo;

- Estruturar o material recolhido da cultura popular para uma dimensão artística;

- Elaborar coreografias para repertório da ETBB.

\section{Objetivos de aprendizagem:}

- Conhecer traços da cultura popular brasileira;

- Dominar a linguagem técnica específica das danças populares de matrizes tradicionais;

- Reconhecer a importância dos movimentos da ancestralidade negra para a dança popular brasileira;

- Pesquisar materiais iconográficos e etnocoreográficos;

- Inventariar o material da pesquisa;

- Reconhecer os materiais da dança tradicional;

- Experenciar e compreender processos de criação em dança popular;

- Aprofundar em moldes laboratoriais as técnicas das danças populares pesquisadas;

\section{Conteúdos:}

- Dança tradicional e dança popular.

- Processos de criação.

- Improvisação.

- Multiculturalismo.

- Linguagem motora e técnica de cada dança popular (frevo, carimbó, coco,maracatu, afoxé, xaxado, dança do peixinho, etc).

- Linguagem simbólica relacionada a cultura popular brasileira. 


\section{T Hsm

ISSN: 1984-6444 | http://dx.doi.org/10.5902/1984644435491

\section{Estratégias:}

Momento de realização de pesquisas teóricas e práticas sobre diferentes danças populares, sublinhando seus contextos de realização, por meio de variadas estratégias:

- Partilha de experiências dos alunos que têm relação com comunidades culturais específicas (conversa, demonstração de fotos, aula prática, etc.);

- Acesso a vídeos e documentários sobre diferentes comunidades culturais;

- Análise e comentários sobre as imagens assistidas e contextos destas comunidades culturais, buscando perceber as diferenças entre as danças;

- Experiências práticas das manifestações estudadas;

- Improvisações orientadas a partir de cada matriz tradicional estudada;

- Promoção de palestras e vivências práticas com convidados;

- Criação de coreografias de danças populares;

- Ensaio de coreografias pertencentes a um repertório já constituído.

Os momentos de improvisação, enquanto procedimento poético das danças populares remete os bailarinos/brincantes para uma melhor percepção contextual e artística das obras. Consequentemente, os movimentos tornam-se autênticos e seu repertório ultrapassa o conjunto de passos ensinados pelo professor. Desta forma, os bailarinos/brincantes deixam de apenas reproduzir gestos de forma mecânica para criar e dar sentido ao que fazem, implicando posicionamentos, sensações, pensamentos e intenções em suas atitudes.

Rito final (Duração estimada: 5 minutos).

Neste momento, os professores devem encorajar os alunos para falar sobre o ocorrido, oferecendo um espaço participativo, capaz de fortalecer a autoconfiança e autonomia de cada estudante. A reflexão em conjunto sobre a prática pedagógica deve considerar a análise crítica dos alunos e da realidade. Isso caracteriza-se por uma forte componente ritualística. Que deste momento os alunos saiam 


\section{T Hsm

ISSN: 1984-6444 | http://dx.doi.org/10.5902/1984644435491

transformados pelo o que experimentaram, com uma nova identidade e posicionamento crítico de sua importância no processo de formação em dança.

\section{Objetivos de ensino:}

- Desenvolver a capacidade de avaliação, crítica e argumentação;

- Praticar a escuta do outro;

- Ampliar as oportunidades de desenvolvimento cognitivo e sócio-afetivo dos participantes;

- Estimular diferentes modos de organização do pensamento;

\section{Objetivos de aprendizagem:}

- Tomar consciência do trabalho realizado em sala de aula;

- Relacionar as práticas realizadas com diferentes aspectos da cultura popular brasileira;

- Instigar curiosidades e a possibilidade de executar novas pesquisas sobre o assunto;

\section{Conteúdos:}

- Espaços de diálogo e troca de experiências.

- Tomada de consciência.

\section{Estratégias:}

A sugestão é realizar uma roda de conversa com os alunos para uma tomada de consciência acerca do que foi desenvolvido/trabalhado na aula. Em círculo, orientase para que os alunos falem brevemente sobre suas impressões, escolha os momentos marcantes, eleja pontos fortes e fracos da experiência vivida. Ao expressarem suas percepções, os alunos sentem-se importantes no processo de conhecimento e adquirem maior confiança em si mesmo. Por outro lado, o professor tem a oportunidade de perceber as impressões dos alunos para melhor planejar a sequência do trabalho. Piaget (1977, p. 197) apresenta que a tomada de consciência não se "reduz simplesmente a um processo de iluminação", e, afirma que "é um 


\section{N Butbapa}

ISSN: 1984-6444 | http://dx.doi.org/10.5902/1984644435491

sistema dinâmico em permanente atividade". É um processo de construção contínuo a partir das relações estabelecidas.

\section{Considerações finais}

O sentido estético e de pertencimento a um grupo assume, nesse trabalho, um sentido educativo, como se pode perceber em várias manifestações populares e tradicionais em todo o Brasil. Há necessariamente a integração entre os componentes do grupo, o reconhecimento do contexto histórico de cada dança, os rituais são acordados (encontros, ensaios, confecção de figurinos e elementos cênicos, pesquisas corporais e culturais), o prazer estético do ato de dançar se torna evidente. Cada um coloca em prática a sua dança. Valorizamos desta forma as palavras de Porpino (2018 p.107) ao dizer que "o aprendizado do dançar, [...] é também aprender o significado do corpo ou da própria vida, em sua impossibilidade de fragmentação". O ensino, por meio desta proposta metodológica, surge como atitude de favorecer experiências de aprendizagem de forma mais envolvente, pois os indivíduos passam a problematizar e compreender as suas próprias histórias, suas raízes. Passam a relacioná-las com a sua existência, podendo durante as aulas agirem criticamente e criativamente nesse novo espaço de convivência que disponta na ETBB.

O contexto do coletivo e do pertencimento a um grupo merece importância nessa proposta, por ser um espaço potente a ser construído com possibilidades de compartilhar diferentes saberes. A pesquisadora Rosa Hercoles (2011) apresenta uma reflexão importante quanto ao processo de formação em dança, considerando a dança como um propósito móvel:

\footnotetext{
Por exemplo: uma coisa é fazer aulas de balé com o propósito final de ser um exímio bailarino, fato que requer a completa formatação do movimento em um tipo definido de configuração neuromuscular, portanto, menos plástica. Outra é fazer esse tipo de aula com o propósito móvel de apreender as instruções de movimento e o conhecimento que elas agregam. Trata-se, portanto, do estudo das estruturas lógicas que operam naquele tipo de linguagem e, isto, é possível de manipulação. (HERCOLES, 2011, p. 28).
} 


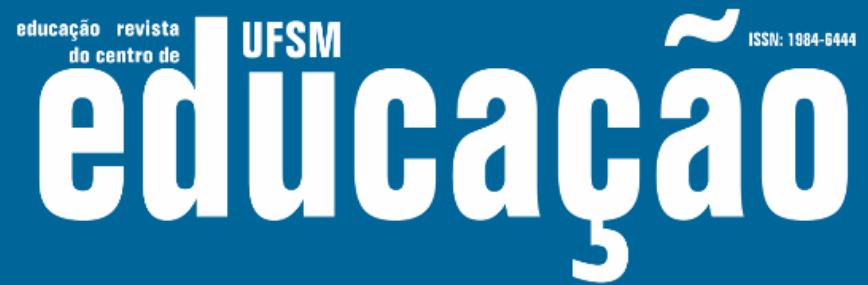

ISSN: 1984-6444 | http://dx.doi.org/10.5902/1984644435491

Fazendo analogia ao pensamento de Hercoles (2011) entendemos que os alunos nas aulas de dança popular de matriz tradicional na ETBB precisarão estar disponíveis corporalmente para conhecer o novo a partir da experimentação e reconhecimento de suas tradições.

Esta proposta metodológica como já mencionado, propõe que os agentes envolvidos no processo (professores e alunos) aprendam a lidar com o improvável, precisando estar preparados para resolver problemas em tempo real. Assim, faz-se necessário continuar percorrendo as múltiplas e complexas redes de saberes, fazeres, poderes, afetos e acontecimentos que se entrecruzam nos cotidianos da ETBB para avançar nessa proposta de compartilhamento de "saberes coletivos", individuais, subjetivos, que podem dialogar com os demais componentes curriculares da ETBB, integrando e valorizando a multiplicidade de corpos que convivem nessa escola. Poderíamos dizer esta proposta seria quase um discurso político, no sentido em que a participação coletiva e democrática seria o ponto chave do processo.

Os professores, dentro desta proposta metodológica, ao estimularem os alunos a ampliar o contato com as estruturas da dança popular brasileira em suas pesquisas, começam a tratar estas aulas como importantes acontecimentos na ETBB e podem provocar transformações nos alunos envolvidos no processo como autonomia e criticidade. A proposta se desenvolveria de maneira relacionada à valorização das manifestações brasileiras, a diferentes possibilidades de movimentações corporais, ao trabalho em grupo, ao respeito às diferentes opiniões, pois dada a nossa experiência nessa área podemos perceber a capacidade de produzir, circular e religar saberes nos corpos que constantemente reelaboram novos sentidos. Sendo assim, acreditamos que seja possível romper alguns paradigmas sobre o ensino da dança popular e sua relação com a corporeidade de cada aluno.

\section{Referências}

BATALHA, A. P. Metodologia do Ensino em Dança. Edições FMH. Lisboa. 2004.

BARBOSA, A. M. A imagem no ensino da arte: anos oitenta e novos tempos. São Paulo: Perspectiva, 1991. 


\section{Aitloab̧ão}

ISSN: 1984-6444 | http://dx.doi.org/10.5902/1984644435491

BOLSHOI, ETBB. Proposta Pedagógica. Joinville, SC. 2014.

BREDEKAMP, S. \& COPPLE, C. Developmentally appropriate practice in early childhood program. (rev. ed.). Washington, DC: NAEYC. 1997.

CARDOSO, S. R. Memórias e jogos tradicionais infantis: lembrar e brincar é só começar. Londrina: Eduel. 2004.

COLL, C. et al. Os conteúdos na reforma. Porto Alegre: Artmed. 2000.

DINIZ, I. C. V. C. Metodologia do ensino da dança: tematizando fatos folclóricos. In: Anais do X Congresso Brasileiro de Ciências do Esporte. v.1. Goiânia, 20 a 25/10, p. 613-618. 1997.

DOLL-JR, W. E. Currículo: uma perspectiva pós-moderna. Porto Alegre: Artes Médicas, 1997.

FREIRE, P. Cartas à Guiné-Bissau. Registros de uma experiência em processo. 4. ed. Rio de Janeiro: Paz e Terra, 1978.

FREIRE, P. Pedagogía del oprimido (18ª Ed.). Madrid: Siglo veintiuno, 2007.

FREIRE, P. Pedagogia da autonomia - Saberes necessários à prática educativa. São Paulo: Paz e Terra, 1996 (Coleção Leitura).

FRIEDMANN, A. Brincar: crescer e aprender - O resgate do jogo infantil. São Paulo: Moderna. 1996.

FUHRMANN, I. V. D. Por que eu danço? Por que tu danças? Por que ele dança?: Um estudo sobre estratégias sociais em contextos escolares de educação complementar. 2008. 182 f. Dissertação (Mestrado em Educação). Universidade Regional de Blumenau, Blumenau. 2008.

GEHRES, A. F. Corpo-Dança-Educação: na contemporaneidade ou da construção de corpos fractais. Instituto Piaget, Lisboa. 2008.

GODOY, K. M. A. (Org.). O desafio de formar plateia para dança. In: Experiências compartilhadas em dança: Formação de plateia. São Paulo: Instituto de Artes da UNESP. p. 73-76. 2013.

KISHIMOTO, T. M. Jogo, Brinquedo, Brincadeira e a Educação. São Paulo: Cortez. 1999.

HERCOLES, R. A não representação do movimento. In: RENGEL, L.; THRALL, K. (Orgs.). Corpo em Cena. Vol. 2. Guararema: Anadarco Editora \& Comunicação, 2011. 


\section{Althapãa}

ISSN: 1984-6444 | http://dx.doi.org/10.5902/1984644435491

LABAN, R. Modern educational dance. 3rd Ed. Plymouth: Northcote House. 1988.

LABAN, R. The mastery of movement. 3rd Ed. Boston: Plays, Inc. 1971.

LIBÂNEO, J. C. Didática. São Paulo: Cortez. 1994.

McCUTCHEN, B. P. Teaching dance as art education. Sheridan Books. 2006.

MARQUES, I. A. Linguagem da dança: arte e ensino. $1^{1}$ ed. São Paulo: Digitexto. 2010.

MARQUES, I. Dançando na escola. 2. ed. São Paulo: Cortez, 2007.

NETO, C. Jogo \& Desenvolvimento da Criança. Lisboa: F.M.H. Edições. 2003.

PERRENOUD, P. Ofício de aluno e sentido do trabalho escolar.

Porto: Porto Editora, 1995.

PIAGET, J. A tomada de consciência. São Paulo: Melhoramentos. 1977.

PORPINO, K. de O. Dança é educação: interfaces entre corporeidade e estética. 2. ed. - Natal, RN: EDUFRN, 2018.

POZO, J.I. Aprendizes e mestres. A nova cultura da aprendizagem. Porto Alegre, Artmed, 2003.

RENGEL, L. P. Corponectividade: comunicação por procedimento metafórico nas mídias e na educação. 2007. 169 f: il. Tese (Doutorado em Comunicação e Semiótica). Pontifícia Universidade Católica de São Paulo.

RENGEL, L.; LUCENA, A. Ação corporal labaniana com respeito ao comum. Anais do IV Congresso da Associação Nacional de Pesquisadores em Dança ANDA, 2015.

RODOLPHO, A. L. Rituais, ritos de passagem e de iniciação: uma revisão da bibliografia antropológica. Estudos Teológicos, São Leopoldo. v. 44, n. 2, p. 138146. 2004.

SANTOS, A. P. O contributo da dança no desenvolvimento da coordenação nas crianças e jovens. Porto: Ana Santos. Dissertação de Mestrado apresentada à Faculdade de desporto da Universidade do Porto. 1997.

SAWAIA, B. B. Transformação social: Um objeto pertinente à psicologia social? Psicologia e Sociedade, v.26, n. spe. 2, p. 4-17. 2014. 


\section{工二F Usm EutlaghaO}

ISSN: 1984-6444 | http://dx.doi.org/10.5902/1984644435491

SHAPIRO, S. Dance, Power and Difference: Critical and Feminist Perspectives on Dance Education. Champaign: Human Kinetics. 1998.

SHAPIRO, S. B. Toward transformative teachers: feminist perspective in dance education. Impulse, The International Journal for Dance Science, Medicine, and Education. n. 4, p.37-47. 1996.

\section{SIMÃO. V. L. Formação Continuada e várias vozes do professorado de}

Educação Infantil de Blumenau: uma proposta vinda de dentro. Atos de Pesquisa em Educação. v. 7, n. 2, mai./ago. p. 626-648. 2012.

SMITH-AUTARD, J. M. The art of dance in education. 2nd ed. London: A \& C Black Publisher. 2002.

TORRE, S. de la, (Col. Ferres, Vicente y Barrios, Charo. Formación del profesorado y cambio). Cómo innovar en los centros educativos. Estudio de casos. Madrid: Escuela Española, 1998.

VAN GENNEP, A. The Rites of Passage by Arnold van Gennep. Routledge Library edition. 2004.

WARDLE, F. Tomorrow's Children: Meeting the needs of multiracial and multiethnic children at home, early childhood programs, and at school. Denver, CO: Center for the Study of Biracial Children. 1999.

ZABALA, A. A prática educativa: como ensinar. Porto Alegre: Editora Artes Médicas Sul Ltda. 1998

\section{Correspondência}

Marco Aurelio da Cruz Souza - Universidade Regional de Blumenau, Rua Antônio da Veiga, 140, Itoupava Seca, CEP 89030-903, Blumenau, Santa Catarina, Brasil.

\section{Notas}

\footnotetext{
${ }^{1}$ Abreviação para Escola do Teatro Bolshoi no Brasil.

2 Projeto Político e Pedagógico, Proposta Pedagógica, folders e programas de espetáculos da ETBB, fotografias dos catálogos da ETBB, e-mails trocados com a coordenadora pedagógica e vídeos institucionais.

${ }^{3}$ Utilizamos o conceito de Sérgio (2003a, p. 130) que indica que o corpo "[...] é o lugar onde eu me experimento como existente". Existir entendido como agir, buscar rumo, ser ativo na sua individualidade, subjetividade e no fazer coletivo.
}

${ }^{4}$ Visa a aprendizagem de novos conhecimentos pela percepção do movimento. 


\section{N

ISSN: 1984-6444 | http://dx.doi.org/10.5902/1984644435491

${ }^{5}$ Acredita que os objetivos podem ser alcançados por meio de formas de relacionamento entre as pessoas envolvidas no processo.

${ }^{6}$ Pelas formas expressivas que são exercitadas nas aulas.

${ }^{7}$ Pelo desenvolvimento das capacidades físicas (coordenação motora, flexibilidade, resistência, força).

${ }^{8}$ Escrito em 1909.

9 Por comunidade cultural entendemos: convivência de pessoas de diferentes localidades, as quais mantém vivas as tradições e manifestações das diferentes regiões de proveniência, como o frevo, maracatú, boi, xaxado, etc.

10 Os ritos simpáticos se pautam na perspectiva da ação de objetos que possuem certa relação ou proximidade.

${ }^{11}$ Os ritos de contágio se baseiam na materialidade e na transmissibilidade, isto é, à distância, das qualidades naturais ou adquiridas.

12 Os ritos são diretos quando têm uma eficiência imediata e automática, já os indiretos dependem da intervenção de um agente para desenvolver um efeito.

${ }^{13}$ Os ritos positivos são atos determinados pela vontade, e os negativos, opostamente, são os atos de querer em contrapartida aos positivos.

${ }^{14}$ Implica o conhecimento das diferentes partes do corpo que produzem o movimento, as quais podem ser identificadas de acordo com princípios anatômicos (lado esquerdo ou direito). Ao mesmo tempo, supõe rastrear os pontos de suporte utilizados, pois o peso do corpo muda de lugar por meio de transferências (andar, correr, pular, girar, etc.) e habilidades (equilíbrio, gestos, flexões, extensões, etc.).

${ }^{15}$ Sugere tomar consciência e descrever as direções, níveis e caminhos de movimento, dado que o corpo e suas partes se movimentam no espaço pessoal (espaço ao redor do corpo) ou no espaço geral (o espaço circundante).

${ }^{16}$ Mudanças qualitativas no movimento podem ser identificadas por meio do conceito de Esforço. Laban (1988) define quatro fatores de movimento para estudar sua dinâmica: peso (o movimento pode ser especificado como leve ou forte), tempo (qualidade súbita ou sustentada), fluxo (livre ou contido) e espaço (direto/foco único ou indireto/multifocal).

17 Por meio do conceito de Relações, define-se o arranjo das partes do corpo em relação a um ou outro corpo e objetos. Tal terminologia é absolutamente necessária uma vez que se refere à plasticidade do movimento e, portanto, às possíveis mudanças na sua forma (isto é, como a perna esquerda se move em relação à direita, como os dançarinos se relacionam entre si, etc.).

${ }^{18}$ São os rituais que acontecem dentro de um tempo social mais amplo estabelecido na forma dos nossos calendários.

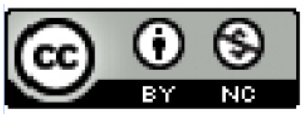

This work is licensed under a Creative Commons Attribution-NonCommercial 4.0 International (CC BY-NC 4.0) 